\title{
Epidemiology analysis of the incidence of severe maternal outcomes between level 2 and 3 hospitals in China's Hunan province from 2012 to 2018
}

Liu zhiyu ( $\Delta 15172112 @ q q . c o m$ )

Maternal and Children Health Care Hospital of Hunan

Xiong Lili

Hunan province maternal and children hospital

Wang Aihua

Hunan province maternal and children hospital

Zeng Mengjun

Hunan province maternal and children hospital

Wu Yinglan

Hunan province maternal and children hospital

Xie Donghua

Hunan province maternal and children hospital

Kong Fanjuan

hunan province maternal and children hospital

Wang Hua

Hunan province maternal and children hospital

\section{Research article}

Keywords: Severe maternal outcomes, Maternal near miss, Maternal deaths, Incidence, Epidemiology, Hunan province

Posted Date: April 24th, 2020

DOI: https://doi.org/10.21203/rs.3.rs-23689/v1

License: @ (i) This work is licensed under a Creative Commons Attribution 4.0 International License. Read Full License 


\section{Abstract}

Background: This facility-based study analyzed the epidemiology and incidence of maternal near-miss (MNM) and mortality by hospital level as part of Hunan province's efforts to raise the quality of hospital care for women.

Methods: We used data for MNM and mortality cases for 2012-2018 from 17 hospitals (12 level 2 facilities, five level 3 facilities) that receive referrals for obstetric complications in Hunan province. Data were drawn from China's National Maternal Near Miss Surveillance System, and collected using the World Health Organization near-miss tool. We calculated the ratio of severe maternal outcomes (SMO) (i.e., MNM and maternal death [MD] cases), mortality index (MI), and MNM to mortality ratio (MNM:MD), and epidemiological factors, organ dysfunction, and maternal complications stratified by hospital level. Chi-square tests to examine differences between groups and total ratios and $95 \% \mathrm{Cl}$ were calculated.

Results: There were 518 SMO cases (489 MNM and 29 MD) among 279407 live births (LBs) and 1299 SMO cases(1262 MNM and $37 \mathrm{MD}$ ) among $232386 \mathrm{LBs}$ in level 2 and 3 facilities. The total MNM ratio in level 2 and 3 hospitals was 1.75 (95\% Cl: 1.60-1.91) and 5.43 (95\%Cl: 5.14-5.74) per 1000 LBs, respectively. There were differences in SMO cases between level 2 and 3 hospitals in maternal age, education, parity, antenatal visits, and history of cesarean sections. In MNM cases, coagulation dysfunction was the main organ dysfunction (level 2 hospitals: 59.10\%; level 3 hospitals: 79.32\%), and the main maternal complications were obstetric hemorrhage (level 2 hospitals: 71.98\%) and hepatopathy (level 3 hospitals: 69.49\%). For MD cases, the main maternal complications were neurologic dysfunction (level 2 hospitals: $41.38 \%$ ) and coagulation dysfunction (level 3 hospitals: $42.55 \%$ ). Anemia was the main maternal complication for SMO cases in both level 2 (69.69\%) and $3(68.59 \%)$ hospitals.

Conclusions: MNM and MD is higher in level 3 hospitals compared with level 2 hospitals. The obstetric emergency capacity of level 3 hospitals is higher than that of level 2 hospitals. Future government policies should consider upgrading the obstetric emergency treatment capacity in level 2 hospitals or to re-distinguish the social functions of different medical institutions.

\section{Background}

The maternal mortality ratio (MMR) represents the number of maternal deaths per 100,000 live births (LBs), and is a core indicator of a country's health and social development. Many countries have reported decreasing MMRs in the context of economic development and improved population health. The Global Burden of Disease study showed that over the last decade, the MMR fell by about 30\% worldwide, from 288 in 2000 to 196 in 2015[1]. Maternal mortality also declined by 8.9\% per year between 1997 and 2014 in China, which has achieved Millennium Development Goal 5 (i.e., a 75\% reduction the MMR between 1990 and 2015)[2]. The MMR in China's Hunan province declined by 45.24\% between 2009 and 2014[3]. Today, maternal death (MD) has become an extremely low probability event in developed countries and parts of developing countries, although severe maternal morbidity or maternal near-miss (MNM) cases remain major public health challenges for healthcare systems globally[4]. MNM is defined by the World Health Organization (WHO) as "a women who nearly died but survived a complication that occurred during pregnancy, childbirth or within 42 days of termination of pregnancy"[5-7]. The concept of MNM as developed by the WHO has been used to assess life-threatening conditions during pregnancy, labor, and puerperium to enable interventions to be focused on the chain of events leading to a woman's near-miss or death[8, 9]. Prevention of MNM is now a major focus in countries with a low MMR, as it offers a means to improve the quality of maternal healthcare[10]. Assessment of pregnant women with severe maternal outcomes (SMO), which includes MNM and MD, may contribute to accelerating the reduction of morbidity and mortality[11]. The WHO recommends that countries should closely monitor SMO trends to identify preventable causes as well as system- and providerrelated failures [12].

Progress has been made in reducing MD in Hunan province[3]. However, there have been no official reports of SMO or MNM cases in Hunan province. Additionally, regional disparities in maternal and child health persist in areas of China, particularly in hospitals, and no study has explored the incidence of SMO and MNM in different levels of medical institutions. However, evaluation of SMO is an important indicator that can help to improve quality of maternal care[13].

This study aimed to compare the incidence and epidemiological characteristics of SMO cases in selected level 2 and 3 hospitals in Hunan province, China, from January 1, 2012 to December 31, 2018. It is important to understand the incidence and epidemiology of SMO cases in different institutions to provide a basis for the government when developing policies concerning prevention of 
maternal deaths and improvement of obstetrical diagnosis and treatment across different levels of medical and health institutions.

\section{Methods}

\section{Aim}

This study aimed to analyze the differences in incidence and epidemiological characteristics of SMO cases between level 2 and 3 hospitals in Hunan province, China, from 2012 to 2018.

\section{Research Design}

This study used a prospective descriptive design based on data for Hunan province collected from China's National Maternal Near Miss Surveillance System (NMNMSS) for 2012-2018. This study dynamically monitored the occurrence of SMO in different levels of medical institutions.

\section{Setting}

Hunan province is located in central China, has a population of 71.47 million people, and covers an area of $21.18 \mathrm{~km}^{2}$. This study included data for 12 level 2 hospitals and five level 3 hospitals. The 17 hospitals have been the maternal near miss surveillance hospitals of Hunan province in China's National Maternal Near Miss Surveillance Program. Level 3 medical institutions are the highest level recognized in China. These medical institutions are considered better than level 2 institutions in terms of the organization size, rate of use of obstetric beds, available human resources, and first aid and service capacity.

\section{Participants' Characteristics}

The participants evaluated in this study were pregnant and postpartum women admitted to the obstetrics departments or intensive care units of the studied institutions, and those who died in hospital. We excluded pregnant women hospitalized in departments other than obstetrics and those with minor abdominal pain but no other obstetric complications. Women that required only embryo preservation (e.g., after in vitro fertilization procedures) and traditional Chinese medicine treatment were also excluded.

The study population included all women during pregnancy, childbirth, or within 42 days of termination of pregnancy regardless of age. Identification of MNM cases was based on the presence of 25 organ and system dysfunction criteria (cardiovascular, respiratory, renal, coagulation, hepatic, neurological, and uterine) via clinical-, laboratory-, and management-based parameters. We defined MNM cases as "a women who nearly died but survived a complication that occurred during pregnancy, childbirth, or within 42 days of termination of pregnancy." MD was defined as "the death of a woman while pregnant, or within 42 days of the termination of pregnancy, irrespective of the duration and site of the pregnancy, from any cause related to, or aggravated by, the pregnancy or its management but not from accidental or incidental causes" [14].

\section{Data Collection}

Data were drawn from China's NMNMSS for a 7-year period from January 1, 2012 to December 31, 2018. The NMNMSS was established in October 2010, and covers 17 health facilities in Hunan province. The system aims to enumerate all MD and MNM cases based on the WHO near miss criteria. Data were collected through a review of all research objects from admission to the obstetrics and gynecology units to discharge. The 17 hospitals were selected by health administration departments of Hunan provincial to monitor levels and causes of child and maternal mortality within the province. The NMNMSS sampling methods have been described in detail elsewhere[15]. Doctors responsible for patient care within each facility were trained to collect and record the main information for maternal cases admitted to the obstetrics departments from admission to discharge. The information collected included maternal socio demographic characteristics, pregnancy termination conditions or complications, rescue 
measures and procedures, and maternal and perinatal outcomes during pregnancy, delivery, and post-partum. Collected data for women that met the inclusion criteria were entered into the NMNMSS. Quality assurance was ensured by county-, municipal-, and provincial-level maternal and child health hospital staff. If surveillance hospital errors exceed a predefined standard (e.g., if obstetric complications were under-reported by more than 5\%, MD was under-reported by more than 1\%, or MNM was underreported by more than $5 \%$, they re-examined all data in the process of quality checking.

The primary outcome indicators were SMO ratio, MNM ratio, MMR, and mortality index (MI). SMO cases included MNM and MD cases, and referred to a life threatening condition (i.e., organ dysfunction or death). The SMO ratio is the number of MNM cases plus MD cases per 1000 LBs. The MNM ratio refers to the number of MNM cases per 1000 LBs. The MMR represents the number of MD cases per 100,000 LBs. The MNM mortality ratio (MNM:MD) refers to the ratio of MNM to MD cases. Finally, the MI refers to the number of MD cases divided by the sum of MNM and MD expressed as a percentage (MI = MD / [MNM + MD]). The SMO and MNM ratios give an estimate of the amount of care and resources that would be needed in an area or facility. SMO ratio, MNM:MD, and $\mathrm{MI}$ are indicators for obstetric quality; the higher the $\mathrm{MI}$ and SMO ratios, more women with life-threatening conditions die (low quality of obstetric care). Conversely, the higher the MNM:MD, fewer women with life-threatening conditions die (better quality of obstetric care).

We reviewed relevant NMNMSS data from January 1, 2012 to December 31, 2018. Next, we exported data from the NMNMSS to IBM SPSS version 20.0 for our analyses. In total, data of 1817 SMO cases from 541128 hospitalized pregnant women were used to analyze in this study. Frequency tables and cross tabulations by level 2 and level 3 hospitals were produced based on the collected demographic and clinical variables. All statistical tests were considered significant at $P<.05$. This study was approved by the Ethic Review Committee of Hunan Province Maternal and Children Health Care Hospital. The requirement for obtaining informed consent was waived because of the retrospective design of this study. This study was carried out in accordance with the principles of the Declaration of Helsinki. Hunan Province Maternal and Children Health Care Hospital is a comprehensive maternal and child care institution responsible for women's and children's healthcare in Hunan province.

\section{Results}

\section{Incidence of SMO}

During the 7-year period, 541,128 pregnant women were hospitalized in the 17 studied hospitals. There were 511,793 LBs, which resulted in $1817 \mathrm{SMO}$ cases. The total SMO ratio and $95 \%$ confidence interval $(\mathrm{Cl})$ in level 2 hospitals was 1.85 (95\% Cl: 1.70-2.02) per 1000 LBs and in level 3 hospitals was 5.59 (95\%Cl: 5.29-5.90) per 1000 LBs. There were 489 MNM cases and 29 MD cases in level 2 hospitals, and 1262 MNM cases and 37 MD cases in level 3 hospitals. The total MNM ratio was 1.75 (95\% Cl: 1.60-1.91) and 5.43 (95\% Cl: 5.14-5.74) per 1000 LBs in level 2 and 3 hospitals, respectively. The total MMR was 10.38 (95\% Cl: 6.95-14.90) and 15.92 (95\% Cl: $11.51-21.95)$ per 100,000 LBs in level 2 and 3 hospitals, respectively. In level 2 hospitals, the total MI was $5.60 \%$ and the MNM ratio was 16.86 . In level 3 hospitals, the total MI was $2.85 \%$ and the MNM ratio was 34.11 . A summary of deliveries and SMO and MNM indicators in level 2 and 3 hospitals is presented in Table 1. We observed that the MNM ratio and MNM:MD in level 2 hospitals declined from 2014 to 2018, whereas the MNM ratio, MNM:MD, and MMR in level 3 hospitals fluctuated during the 7 year period (Fig. 1) 
Table 1

Summary of deliveries, severe maternal outcomes, and near miss indicators in women admitted to level 2 and 3 hospitals in Hunan province from 2012 to 2018

\begin{tabular}{|c|c|c|c|c|c|c|c|c|}
\hline level 2 & Total & 2012 & 2013 & 2014 & 2015 & 2016 & 2017 & 2018 \\
\hline $\begin{array}{l}\text { All hospitalized pregnant } \\
\text { women(number) }\end{array}$ & 296985 & 37227 & 40216 & 43523 & 43536 & 47883 & 47529 & 37071 \\
\hline liver births(number) & 279407 & 36095 & 38085 & 40600 & 41237 & 45250 & 44566 & 33574 \\
\hline Pregnancy complications (number) & 124791 & 4638 & 12007 & 18285 & 20061 & 23705 & 23317 & 22778 \\
\hline $\begin{array}{l}\text { Severe maternal outcome cases } \\
\text { (number) }\end{array}$ & 518 & 75 & 86 & 68 & 76 & 54 & 82 & 77 \\
\hline Maternal near- miss cases (number) & 489 & 71 & 83 & 65 & 72 & 50 & 76 & 72 \\
\hline Maternal death cases (number) & 29 & 4 & 3 & 3 & 4 & 4 & 6 & 5 \\
\hline \multicolumn{9}{|l|}{ Overall near-miss indicators } \\
\hline $\begin{array}{l}\text { Severe maternal outcome ratio (per } \\
1000 \text { live births) } 95 \% \mathrm{Cl}\end{array}$ & $\begin{array}{l}1.85(1.70- \\
2.02)\end{array}$ & 2.08 & 2.26 & 1.67 & 1.84 & 1.19 & 1.84 & 2.29 \\
\hline $\begin{array}{l}\text { Maternal near-miss ratio (per } 1000 \text { live } \\
\text { births) } 95 \% \mathrm{Cl}\end{array}$ & $\begin{array}{l}1.75(1.60- \\
1.91)\end{array}$ & 1.97 & 2.18 & 1.60 & 1.75 & 1.10 & 1.71 & 2.14 \\
\hline $\begin{array}{l}\text { Maternal mortality ratio(per } 100000 \\
\text { live births) } 95 \% \mathrm{Cl}\end{array}$ & $\begin{array}{l}10.38(6.95- \\
14.90)\end{array}$ & 11.08 & 7.88 & 7.39 & 9.70 & 8.84 & 13.46 & 14.89 \\
\hline $\begin{array}{l}\text { Maternal near-miss mortality ratio } \\
\text { (MNM:MD) }\end{array}$ & 16.86 & 17.75 & 27.67 & 21.67 & 18.00 & 12.50 & 12.67 & 14.40 \\
\hline Mortality index (\%) & 5.60 & 5.33 & 3.49 & 4.41 & 5.26 & 7.41 & 7.32 & 6.49 \\
\hline level 3 & total & 2012 & 2013 & 2014 & 2015 & 2016 & 2017 & 2018 \\
\hline $\begin{array}{l}\text { All hospitalized pregnant } \\
\text { women(number) }\end{array}$ & 244143 & 24659 & 26846 & 31675 & 35285 & 44175 & 43699 & 37804 \\
\hline liver births(number) & 232386 & 24086 & 25604 & 30262 & 33684 & 42108 & 41383 & 35259 \\
\hline Pregnancy complications (number) & 149997 & 4711 & 11426 & 19518 & 21912 & 29997 & 33091 & 29342 \\
\hline $\begin{array}{l}\text { Severe maternal outcome cases } \\
\text { (number) }\end{array}$ & 1299 & 111 & 175 & 182 & 168 & 222 & 200 & 241 \\
\hline Maternal near- miss cases (number) & 1262 & 108 & 170 & 177 & 161 & 216 & 193 & 237 \\
\hline Maternal death cases (number) & 37 & 3 & 5 & 5 & 7 & 6 & 7 & 4 \\
\hline \multicolumn{9}{|l|}{ Overall near-miss indicators } \\
\hline $\begin{array}{l}\text { Severe maternal outcome ratio (per } \\
1000 \text { live births) } 95 \% \mathrm{Cl}\end{array}$ & $\begin{array}{l}5.59(5.29- \\
5.90)\end{array}$ & 4.61 & 6.83 & 6.01 & 4.99 & 5.27 & 4.83 & 6.84 \\
\hline $\begin{array}{l}\text { Maternal near-miss ratio (per } 1000 \text { live } \\
\text { births) } 95 \% \mathrm{Cl}\end{array}$ & $\begin{array}{l}5.43(5.14- \\
5.74)\end{array}$ & 4.48 & 6.64 & 5.85 & 4.78 & 5.13 & 4.66 & 6.72 \\
\hline $\begin{array}{l}\text { Maternal mortality ratio(per } 100000 \\
\text { live births) } 95 \% \mathrm{Cl}\end{array}$ & $\begin{array}{l}15.92(11.51- \\
21.95)\end{array}$ & 12.46 & 19.53 & 16.52 & 20.78 & 14.25 & 16.92 & 11.34 \\
\hline $\begin{array}{l}\text { Maternal near-miss mortality ratio } \\
\text { (MNM:MD) }\end{array}$ & 34.11 & 36.00 & 34.00 & 35.40 & 23.00 & 36.00 & 27.57 & 59.25 \\
\hline Mortality index (\%) & 2.85 & 2.70 & 2.86 & 2.75 & 4.17 & 2.70 & 3.50 & 1.66 \\
\hline
\end{tabular}


The majority (31.15\%) of SMO cases in both level 2 and 3 hospitals occurred among women aged 30-34 years. The highest proportion (48.76\%) of cases was recorded as having a high school education. Only $2.20 \%$ of cases were not married at the time of the investigation, and nearly half was their second pregnancy. The antenatal visits of the cases of SMO grouped by level 2 and 3 were $4-6$ times (34.75\%) and 7-9 times (40.88\%) differently $\left(\chi^{2}=121.42, P=0.104\right)$. More SMO cases in level 3 institutions had a history of cesarean section delivery. There was no difference in the marital status in SMO cases by hospital level $\left(\chi^{2}=2.65, P=\right.$ 0.104) (Table 2). 
Table 2

Personal information for women with severe maternal outcomes at level 2 and 3 hospitals in Hunan province, from 2012 to 2018.

\begin{tabular}{|c|c|c|c|c|c|c|}
\hline \multirow[t]{2}{*}{ Variables } & \multicolumn{2}{|c|}{ Level 2} & \multicolumn{2}{|c|}{ Level 3} & \multirow{2}{*}{$x^{2}$} & \multirow[t]{2}{*}{$P$} \\
\hline & $\mathbf{N}$ & $\%$ & $\mathbf{N}$ & $\%$ & & \\
\hline \multicolumn{5}{|l|}{ Mother's age(years) } & \multirow[t]{8}{*}{35.263} & \multirow[t]{8}{*}{$<0.001$} \\
\hline$<20$ & 17 & 3.28 & 13 & 1.00 & & \\
\hline $20-24$ & 68 & 13.13 & 100 & 7.70 & & \\
\hline $25-29$ & 149 & 28.76 & 405 & 31.18 & & \\
\hline $30-34$ & 126 & 24.32 & 440 & 33.87 & & \\
\hline $35-39$ & 80 & 15.44 & 222 & 17.09 & & \\
\hline$\geq 40$ & 33 & 6.37 & 91 & 7.01 & & \\
\hline Missing & 45 & 8.69 & 28 & 2.16 & & \\
\hline \multicolumn{5}{|l|}{ Mother's education } & \multirow[t]{6}{*}{318.1} & \multirow[t]{6}{*}{$<0.001$} \\
\hline None/Primary school & 30 & 5.79 & 21 & 1.62 & & \\
\hline Middle school & 187 & 36.10 & 117 & 9.01 & & \\
\hline High school & 249 & 48.07 & 637 & 49.04 & & \\
\hline College or higher & 34 & 6.56 & 504 & 38.80 & & \\
\hline Missing & 18 & 3.47 & 20 & 1.54 & & \\
\hline \multicolumn{5}{|l|}{ Marital status } & \multirow[t]{3}{*}{2.65} & \multirow[t]{3}{*}{0.104} \\
\hline Single, widowed, or divorced & 16 & 3.09 & 24 & 1.85 & & \\
\hline Married & 502 & 96.91 & 1275 & 98.15 & & \\
\hline \multicolumn{5}{|l|}{ Parity } & \multirow[t]{4}{*}{9.063} & \multirow[t]{4}{*}{0.011} \\
\hline 0 & 181 & 34.94 & 544 & 41.88 & & \\
\hline 1 & 265 & 51.16 & 618 & 47.58 & & \\
\hline$\geq 2$ & 72 & 13.90 & 137 & 10.55 & & \\
\hline \multicolumn{5}{|l|}{ Antenatal visits } & \multirow[t]{7}{*}{121.42} & \multirow[t]{7}{*}{$<0.001$} \\
\hline 0 & 15 & 2.90 & 14 & 1.08 & & \\
\hline $1-3$ & 87 & 16.80 & 116 & 8.93 & & \\
\hline $4-6$ & 180 & 34.75 & 294 & 22.63 & & \\
\hline $7-9$ & 125 & 24.13 & 531 & 40.88 & & \\
\hline$\geq 10$ & 42 & 8.11 & 296 & 22.79 & & \\
\hline Missing & 68 & 13.13 & 48 & 3.70 & & \\
\hline \multicolumn{5}{|l|}{ History of caesarean sections } & \multirow[t]{3}{*}{14.679} & \multirow[t]{3}{*}{$<0.001$} \\
\hline Yes & 138 & 26.64 & 468 & 36.03 & & \\
\hline NO & 380 & 73.36 & 831 & 63.97 & & \\
\hline
\end{tabular}




\section{Termination Of Pregnancy Among Women With Smo}

Most deliveries among women with SMO were at 37-42 gestational weeks in level 2 (56.56\%) and level 3 (48.19\%) hospitals. In total, 111 SMO cases (21.43\%) in level 2 hospitals and $36.26 \%$ SMO cases in level 3 hospitals delivered low birth weight infants. Additionally, cesarean section was chosen in $61.39 \%$ SMO cases in level 2 hospitals and $70.67 \%$ cases in level 3 hospitals. Most SMO cases in level 3 hospitals (94.30\%) had delivered at provincial hospitals, and $87.26 \%$ SMO cases in level 2 hospitals had delivered at county hospitals. The rate of LBs in level 3 hospitals (92.38\%) was higher than that in level 2 hospitals (82.43\%) (Table 3). 
Table 3

Termination of pregnancy for cases with severe maternal outcomes at level 2 and 3 hospitals in Hunan province, from 2012 to 2018.

\begin{tabular}{|c|c|c|c|c|}
\hline \multirow[t]{2}{*}{ Variables } & \multicolumn{2}{|c|}{ Level 2} & \multicolumn{2}{|c|}{ Level 3} \\
\hline & $\mathbf{N}$ & $\%$ & $\mathbf{N}$ & $\%$ \\
\hline \multicolumn{5}{|l|}{ Gestational age (weeks) } \\
\hline$<28$ & 52 & 10.04 & 107 & 8.24 \\
\hline $29-36$ & 105 & 20.27 & 505 & 38.88 \\
\hline $37-42$ & 293 & 56.56 & 626 & 48.19 \\
\hline Missing & 68 & 13.13 & 61 & 4.70 \\
\hline \multicolumn{5}{|l|}{ Birth weight (grams) } \\
\hline$\bowtie 2500$ & 111 & 21.43 & 471 & 36.26 \\
\hline $2500-4000$ & 298 & 57.53 & 744 & 57.27 \\
\hline$\geq 4000$ & 32 & 6.18 & 51 & 3.93 \\
\hline Missing & 103 & 19.88 & 145 & 11.16 \\
\hline \multicolumn{5}{|c|}{ Mode of delivery/ End of pregnancy } \\
\hline Vaginal delivery & 124 & 23.94 & 284 & 21.86 \\
\hline Caesarean Section & 318 & 61.39 & 918 & 70.67 \\
\hline Abortion/ Other & 50 & 9.65 & 62 & 4.77 \\
\hline Missing & 26 & 5.02 & 35 & 2.69 \\
\hline \multicolumn{5}{|l|}{ Place of delivery } \\
\hline Provincial hospital & 4 & 0.77 & 1225 & 94.30 \\
\hline County Hospital & 452 & 87.26 & 19 & 1.46 \\
\hline Township hospital/Others & 25 & 4.83 & 19 & 1.46 \\
\hline Missing & 37 & 7.14 & 36 & 2.77 \\
\hline \multicolumn{5}{|l|}{ Total deliveries } \\
\hline 1 & 459 & 88.61 & 1136 & 87.45 \\
\hline$\geq 2$ & 26 & 5.02 & 111 & 8.55 \\
\hline Unknown/missing & 33 & 6.37 & 52 & 4.00 \\
\hline \multicolumn{5}{|l|}{ Gender } \\
\hline Female & 244 & 47.10 & 645 & 49.65 \\
\hline Male & 225 & 43.44 & 642 & 49.42 \\
\hline Unknown/missing & 75 & 14.48 & 125 & 9.62 \\
\hline \multicolumn{5}{|l|}{ State of birth } \\
\hline Live birth & 427 & 82.43 & 1200 & 92.38 \\
\hline Stillbirth & 44 & 8.49 & 112 & 8.62 \\
\hline Unknown/missing & 73 & 14.09 & 100 & 7.70 \\
\hline
\end{tabular}




\section{Organ Dysfunction And Maternal Complications}

Coagulation dysfunction was reported in 1021 MNM cases (78.60\%) in level 3 hospitals and 297 MNM cases (57.34\%) in level 2 hospitals. The common organ dysfunction associated with MD in was neurologic dysfunction (41.38\%) in level 2 hospitals and coagulation dysfunction (42.55\%) in level 3 hospitals. The highest MI was for neurologic dysfunction in level 2 hospitals (2.32) and coagulation dysfunction in level 3 hospitals (1.54). The most common maternal complications in level 2 hospitals were hypertensive disorder in $18 \mathrm{MD}$ cases and obstetric hemorrhage in 352 MNM cases. In level 3 hospitals, the most common maternal complication was anemia (except unclassified diseases), which was found in 14 MD cases and 877 MNM cases. The highest MI associated with maternal complications was for hypertensive disorder (3.10) in level 2 hospitals and anemia (1.08) in level 3 hospitals, excluding unclassified complications. These outcomes are shown in Table 4 and Fig. 2. 
Table 4

Organ dysfunction and maternal complications for cases with severe maternal outcomes at level 2 and 3 hospitals in Hunan province, from 2012 to 2018.

\begin{tabular}{|c|c|c|c|c|c|c|c|c|}
\hline \multirow{3}{*}{$\begin{array}{l}\text { Organ } \\
\text { dysfunction }\end{array}$} & \multicolumn{4}{|l|}{ Level 2} & \multicolumn{4}{|l|}{ Level 3} \\
\hline & $\begin{array}{l}\text { Maternal } \\
\text { near-miss }\end{array}$ & $\begin{array}{l}\text { Maternal } \\
\text { deaths }\end{array}$ & $\begin{array}{l}\text { Severe } \\
\text { maternal }\end{array}$ & Mortality & $\begin{array}{l}\text { Maternal } \\
\text { near-miss }\end{array}$ & $\begin{array}{l}\text { Maternal } \\
\text { deaths }\end{array}$ & $\begin{array}{l}\text { Severe } \\
\text { maternal }\end{array}$ & Mortality \\
\hline & $(\mathrm{N}=489) \%$ & $(N=29) \%$ & $(N=518) \%$ & & $(N=1262) \%$ & $(N=47) \%$ & $(N=1299) \%$ & \\
\hline $\begin{array}{l}\text { Cardiovascular } \\
\text { dysfunction }\end{array}$ & 221(49.19) & $6(20.69)$ & 227(43.82) & 1.16 & 233(18.46) & $13(27.66)$ & 246(18.94) & 1.00 \\
\hline $\begin{array}{l}\text { Respiratory } \\
\text { dysfunction }\end{array}$ & $37(7.57)$ & $7(24.14)$ & $44(8.49)$ & 1.35 & $90(7.13)$ & $8(17.02)$ & $98(7.54)$ & 0.62 \\
\hline $\begin{array}{l}\text { Renal } \\
\text { dysfunction }\end{array}$ & 19(3.89) & $4(13.79)$ & $23(4.44)$ & 0.77 & $27(2.14)$ & $1(2.13)$ & $28(2.16)$ & 0.08 \\
\hline $\begin{array}{l}\text { Coagulation } \\
\text { dysfunction }\end{array}$ & 289(59.10) & $8(27.59)$ & 297(57.34) & 1.54 & $1001(79.32)$ & $20(42.55)$ & $1021(78.60)$ & 1.54 \\
\hline $\begin{array}{l}\text { Hepatic } \\
\text { dysfunction }\end{array}$ & $6(1.23)$ & $4(13.79)$ & 10(1.93) & 0.77 & $27(2.14)$ & $1(2.13)$ & $28(2.16)$ & 0.08 \\
\hline $\begin{array}{l}\text { Neurologic } \\
\text { dysfunction }\end{array}$ & $89(18.20)$ & $12(41.38)$ & 101(19.50) & 2.32 & $120(9.51)$ & $8(17.02)$ & $128(9.85)$ & 0.62 \\
\hline $\begin{array}{l}\text { Uterine } \\
\text { dysfunction }\end{array}$ & 82(16.77) & $1(3.45)$ & $83(16.02)$ & 0.19 & 172(13.63) & $0(0.00)$ & 171(13.16) & 0.00 \\
\hline \multicolumn{9}{|c|}{ Maternal complications } \\
\hline $\begin{array}{l}\text { Obstetric } \\
\text { hemorrhage }\end{array}$ & 352(71.98) & $3(10.34)$ & $355(68.53)$ & 0.52 & $864(68.46)$ & $7(14.89)$ & $871(67.05)$ & 0.54 \\
\hline $\begin{array}{l}\text { Pregnancy } \\
\text { related } \\
\text { infections }\end{array}$ & $42(8.59)$ & $2(6.90)$ & $44(8.49)$ & 0.34 & $109(8.64)$ & $4(8.51)$ & 113(8.70) & 0.31 \\
\hline $\begin{array}{l}\text { Hypertensive } \\
\text { disorder }\end{array}$ & 146(29.86) & $18(62.07)$ & 164(31.66) & 3.10 & 290(22.98) & $11(23.40)$ & 302(23.25) & 0.85 \\
\hline Heart disease & $12(2.45)$ & $4(13.79)$ & $13(2.51)$ & 0.69 & $58(4.60)$ & $5(10.64)$ & $63(4.85)$ & 0.38 \\
\hline $\begin{array}{l}\text { Embolism } \\
\text { disease }\end{array}$ & $14(2.86)$ & $5(17.24)$ & 16(3.09) & 0.86 & 19(1.51) & $7(14.89)$ & 23(1.77) & 0.54 \\
\hline Hepatopathy & $23(4.70)$ & $3(10.34)$ & $26(5.02)$ & 0.52 & $59(4.68)$ & $3(6.38)$ & $62(4.77)$ & 0.23 \\
\hline Anemia & $350(71.57)$ & 11(37.93) & $361(69.69)$ & 1.89 & $877(69.49)$ & $14(29.79)$ & 891(68.59) & 1.08 \\
\hline $\begin{array}{l}\text { Diabetes } \\
\text { mellitus }\end{array}$ & $37(7.57)$ & $0(0.00)$ & $37(7.14)$ & 0.00 & 202(16.01) & $6(12.77)$ & 208(16.01) & 0.46 \\
\hline Nephropathy & $7(1.43)$ & $3(10.34)$ & 10(1.93) & 0.52 & $31(2.46)$ & $0(0.00)$ & $30(2.31)$ & 0.00 \\
\hline $\begin{array}{l}\text { Pulmonary } \\
\text { disease }\end{array}$ & $2(0.41)$ & $0(0.00)$ & $2(0.39)$ & 0.00 & $28(2.22)$ & $3(6.38)$ & $31(2.39)$ & 0.23 \\
\hline $\begin{array}{l}\text { With other } \\
\text { diseases }\end{array}$ & 275(56.24) & $14(48.28)$ & 289(55.79) & 2.41 & 746(59.11) & 25(53.19) & 783(62.66) & 1.92 \\
\hline
\end{tabular}

\section{Discussion}

\section{Severe maternal outcomes}


The WHO has initiated a process of agreeing on a definition and developing a uniform set of identification criteria for MNM cases, with the intent of facilitating reviews of these cases to monitor and improve the quality of obstetric care[10]. Our study showed the prevalence of MNM was $0.175 \%$ among 296,985 women attending 12 level 2 health facilities, and $0.543 \%$ among 244,143 women attending five level 3 health facilities in Hunan province from 2012 to 2018. Other studies have reported MNM incidence rates from 0.4-1.6\%[16-21]. A systematic review conducted in sub-Saharan Africa on the applicability of the WHO maternal near miss tool showed the median MNM ratio was 24.2 (95\% Cl: 12.4-35.8) per $1000 \mathrm{LBs}$, which ranged from 4.4 in a population-based study in South Africa to 198 in a rural private hospital in Nigeria[22]. A systematic review conducted in sub-Saharan Africa on the applicability of the WHO maternal near miss tool showed the median MNM ratio was 24.2 (95Cl: 12.4-35.8) per 1000 LBs, which ranged from 4.4 in a population-based study in South Africa to 198 in a rural private hospital in Nigeria[23]. Overall, level 3 hospitals in China's Hunan province treat more MNM cases, but the incidence of MNM in this study was lower than that reported in most international studies.

MD constitutes the most obvious manifestation of severe morbidity related to pregnancy, childbirth, and puerperium. Our study showed the prevalence of MD was 10.38/100,000 LBs (29 deaths) in the 12 level 2 facilities, and 15.92/100,000 LBs (37 deaths) in the five level 3 facilities. High maternal mortality was reported in the US, with rates from 16.0 to 17.8 per 100,000 LBs between 2009 and 2016[24]. In Turkey, the MMR was 15.4 deaths per 100,000 LBs in 2012, compared with 13.7 in 2015[25]. In sub-Saharan Africa, the MMR was 351 per 100,000 LBs, which was similar to that in south Asia (336 per 100,000 LBs)[26]. Over the past few decades, substantial progress has been made in safe motherhood, possibly attributable to delivery in hospital policies and prevention and treatment of postpartum hemorrhage programs, although regional inequality persists.

Indicators such as the MNM:MD and MI are also used to describe obstetric care. The MNM:MD represents the proportion of MNM cases that progressed to MD, with a higher ratio reflecting better quality of care[5]. In this study, the MNM:MD was 16.86 and 34.11 in level 2 and 3 hospitals, respectively. Therefore, one MD occurred for every 17 MNM cases in level 2 hospitals and for every 34 MNM cases in level 3 hospitals. MNM cases are more likely to die in non-developed and developing countries than in developed countries. A study conducted in Somaliland and Tanzania using similar WHO criteria reported the MNM:MD was 6.7[27, 28]. However, studies conducted in South Africa such as Nigeria, Tanzania, and Ghana and Pakistan reported near ratios ranging from 1.5 to $5[21,26,29]$. The ratios in our study were relatively high in the context of existing policies to promote maternal and child health.

Our findings revealed a $\mathrm{MI}$ of $5.6 \%$ in level 2 hospitals and $2.85 \%$ in level 3 hospitals, which was comparable to the $4.2 \% \mathrm{MI}$ reported in previous studies conducted in China and Malaysia[19,30]. A low MI $(<5 \%)$ indicates better quality of care, with fewer women with severe conditions dying; in contrast, a high $\mathrm{Ml}(>20 \%)$ indicates low quality obstetric care for severe cases, in which more women with severe conditions die[5].

Based on our comparison of these four indicators, we concluded that level 3 hospitals have a stronger medical treatment ability and better healthcare quality. We suggest upgrading the obstetric emergency treatment capacity in level 2 hospitals or to redistinguish the social functions of different medical institutions, such as implementing graded diagnosis where level 3 hospitals focus on treating MNM cases, and level 2 hospitals focus on monitoring basic health indictors for pregnant women in rural areas and city communities based on the current medical resource and level of critical illness treatment. Results from our analysis may contribute to the development of the healthcare system in China.

\section{Demographic Differences And Birth Outcomes}

This study mainly compared women admitted to level 2 hospitals with those admitted to level 3 hospitals. Overall, the proportion of giving birth to a second child was highest in SMO cases. The phenomenon is due to the background of two-child policy opening and high cesarean section rate in China. The main differences found in the demographic comparisons were in the number of antenatal visits and history of cesarean section. SMO cases in level 3 hospitals had more antenatal visits and a higher proportion of cesarean sections than SMO cases in level 2 hospitals. In addition, $33.35 \%$ of all SMO cases were women with a history of cesarean section, which was less than the $58 \%$ reported in a study at a tertiary referral teaching hospital in the southeast of Iran[31]. Although previous cesarean delivery is not considered a risk factor for SMO or adverse perinatal outcomes, there could be differences between study groups in terms of healthcare-seeking behavior, referral mechanisms, intrapartum monitoring, and

Page $12 / 18$ 
clinical decision making[32]. Considering that level 2 hospitals are located in rural areas and level 3 hospitals are located urban areas, there were fewer antenatal visits for pregnant women living in rural areas. This may be related to health awareness. It may be necessary to improve maternal health knowledge and focus on behavior change in low-resource and limited literacy settings, which may contribute to reductions in maternal mortality[33].

Among the 1817 SMO cases in this study, $51 \%$ cases delivered at $37-42$ gestational weeks, $68 \%$ cases delivered by cesarean section, and $88 \%$ of women were giving birth for the first time. Most newborns were LBs and term infants. Several studies have shown that the presence of MNM in women is strongly associated with the occurrence of adverse perinatal outcomes, such as stillbirth, preterm birth, low birth weight, and early neonatal mortality[34-37]. However, studies that quantified the effect of MNM on adverse perinatal outcomes are scarce in China. We intend to explore this issue in a further study.

\section{Clinical Disorders}

Hypertensive disorders and neurologic dysfunction were responsible for most MD cases in level 2 hospitals, whereas anemia and coagulation dysfunction were most common in MD cases in level 3 hospitals. However, for MNM cases, anemia and coagulation dysfunction were the leading cause of death in both level 2 and 3 hospitals. We found the major causes of SMO were anemia, hypertensive disorder, and obstetric hemorrhage. Hypertensive disorder and cardiovascular dysfunction were the most frequent conditions among MNM cases in Alborz province of Iran, where medical resources are undeveloped[38]. In the stetting of the present study, hypertensive disorders related to MNM cases in level 2 hospitals and anemia in level 3 hospitals need more attention to prevent SMO cases in Hunan province. Anemia in pregnancy is associated with severe maternal morbidity and is an indirect cause of MD across pregnant populations in both low- and high-income settings[39]. The high prevalence of anemia also contributed to adverse outcomes in women with prenatal hemorrhage. It is therefore crucial to optimize maternal iron status to improve maternal outcomes[40]. Postpartum hemorrhage was less common in the present study compared with other studies, which may be because of the high coverage of essential medical interventions to prevent this condition.

\section{Limitations}

We applied the unified WHO maternal near miss criteria in different-sized hospitals, which might have resulted in information bias because of differences in diagnostic capabilities and standards. Second, we used facility-based sampling, which could have introduced referral bias. Third, some related risk factors associated with MNM such as pre-pregnancy body mass index, diseases before pregnancy, and family history were not collected in this study.

\section{Conclusions}

The study shows higher ratios of MNM and MD cases in level 3 hospitals compared with level 2 hospitals. The obstetric emergency capacity of level 3 hospitals is higher than that of level 2 hospitals. Our findings suggest future government policies should consider upgrading the obstetric emergency treatment capacity in level 2 hospitals or to re-distinguish the social functions of different medical institutions.

\section{Abbreviations}

SMO:severe maternal outcomes; MNM:maternal near miss; MD:maternal deaths; MI:mortality index; MNM:MD:the ratio of maternal near miss to mortality; LBs:live births; NMNMSS:China's National Maternal Near Miss Surveillance System; WHO:World Health Organization; Cl:confidence intervals; MMR:maternal mortality ratio.

\section{Declarations}

Ethics approval was obtained from Hunan province maternal and children care hospital.

\section{Consent for publication}




\section{Availability of data and materials}

The datasets used and/or analyzed in the present study are available from the first author on request.

\section{Competing interests}

The authors declare that they have no competing interests.

\section{Funding}

No external funding was obtained for this study.

\section{Authors' contributions}

XLL was primarily responsible for conceiving the project. $\mathrm{WAH}, \mathrm{ZMJ}, \mathrm{WYL}, \mathrm{XDH}$, and $\mathrm{KFJ}$ were responsible for carrying out data collection and analysis of the manuscript. WH and LZY were responsible for reviewing the manuscript.

\section{Acknowledgements}

We thank Audrey Holmes, MA, from Liwen Bianji, Edanz Group China (www.liwenbianji.cn/ac), for editing the English text of a draft of this manuscript. We wish to thank the staffs who had collected, recorded and reviewed the information of maternal near miss surveillance relevant to this study.

\section{References}

1. Global, regional, and national levels of maternal mortality, 1990-2015: a systematic analysis for the Global Burden of Disease Study 2015. 2016.

2. Gao Y, Zhou H, Singh NS, Powell-Jackson T, Nash S, Yang M, Guo S, Fang H, Alvarez MM, Liu X, et al. Progress and challenges in maternal health in western China: a Countdown to 2015 national case study. The Lancet Global Health. 2017;5(5):e523-36.

3. Lili X, Jian H, Mengjun Z, Yinglan W, Donghua X, Aihua W, Fanjuan K, Hua W, Zhiyu L, Das JK. Epidemiological analysis of maternal deaths in Hunan province in China between 2009 and 2014. PLOS ONE, 13(11).

4. Hogan MC, Foreman KJ, Naghavi M, Ahn SY, Wang M, Makela SM, Lopez AD, Lozano R, Murray CJ. Maternal mortality for 181 countries, 1980-2008: a systematic analysis of progress towards Millennium Development Goal 5. 2010, 375(9726):16091623.

5. Organization WH: Evaluating the quality of care for severe pregnancy complications: the WHO near-miss approach for maternal health. 2011.

6. Say L, Souza JoP, Pattinson RC. Maternal near miss - towards a standard tool for monitoring quality of maternal health care. 23(3):287-296.

7. Bacci A, Lewis G, Baltag V, Betrán AP. The Introduction of Confidential Enquiries into Maternal Deaths and Near-Miss Case Reviews in the WHO European Region. 2007, 15(30):145-152.

8. Kiruja J, Osman F, Egal JA, Essén B, Klingberg-Allvin M, Erlandsson K. Maternal near-miss and death incidences Frequencies, causes and the referral chain in Somaliland: A pilot study using the WHO near-miss approach. Sexual \& Reproductive Healthcare, 12:30-36.

9. Stacie E, Geller, and, Deborah, Rosenberg, and, Suzanne M. Cox: The continuum of maternal morbidity and mortality: Factors associated with severity. 
10. Say L, Souza JP, Pattinson RC. Maternal near miss-towards a standard tool for monitoring quality of maternal health care. Best practice research Clinical obstetrics gynaecology. 2009;23(3):287-96.

11. Souza JP, Gülmezoglu AM, Vogel J, Carroli G, Lumbiganon P, Qureshi Z, Costa MJ, Fawole B, Mugerwa Y, Nafiou I. Moving beyond essential interventions for reduction of maternal mortality (the WHO Multicountry Survey on Maternal and Newborn Health): a cross-sectional study. The Lancet. 2013;381(9879):1747-55.

12. Say L, Pattinson RC, Gülmezoglu AM: WHO systematic review of maternal morbidity and mortality: the prevalence of severe acute maternal morbidity (near miss). Reproductive Health 2004, 1(1):3.

13. Tunçalp Ö, Souza J. Maternal near-miss audits to improve quality of care. Bjog An International Journal of Obstetrics Gynaecology. 2014;121(Suppl 4(s4):102-4.

14. Alkema L, Chou D, Hogan D, Zhang S, Moller A-B, Gemmill A, Fat DM, Boerma T, Temmerman M, Mathers C, et al. Global, regional, and national levels and trends in maternal mortality between 1990 and 2015, with scenario-based projections to 2030: a systematic analysis by the UN Maternal Mortality Estimation Inter-Agency Group. The Lancet. 2016;387(10017):46274.

15. Zhu J, Liang J, Mu Y, Li X, Guo S, Scherpbier R, Wang Y, Dai L, Liu Z, Li M, et al. Sociodemographic and obstetric characteristics of stillbirths in China: a census of nearly 4 million health facility births between 2012 and 2014. The Lancet Global Health. 2016;4(2):e109-18.

16. Pacheco AJ, Katz L, Souza AS, de Amorim MM. Factors associated with severe maternal morbidity and near miss in the São Francisco Valley, Brazil: a retrospective, cohort study. BMC pregnancy and childbirth 2014, 14.

17. Galvão LPL, Alvim-Pereira F, Mendonça CMMD, Menezes FEF, Gurgel RQ. The prevalence of severe maternal morbidity and near miss and associated factors in Sergipe, Northeast Brazil. Bmc Pregnancy Childbirth. 2014;14(1):25.

18. Incidence and determinants of severe maternal morbidity: a transversal study in a referral hospital in Teresina, Piaui, Brazil. BMC pregnancy and childbirth, 15(1):210.

19. Norhayati MN, Nik Hazlina NH, Sulaiman Z, Azman MY. Severe maternal morbidity and near misses in tertiary hospitals, Kelantan, Malaysia: a cross-sectional study. BMC Public Health. 2016;16:229.

20. Moving Beyond Essential Interventions for Reduction of Maternal Mortality (the WHO Multicountry Survey on Maternal and Newborn Health). Obstetric Anesthesia Digest 2014.

21. Oladapo O, Adetoro O, Ekele B, Chama C, Etuk S, Aboyeji A, Onah H, Abasiattai A, Adamu A, Adegbola O. When getting there is not enough: a nationwide cross-sectional study of 998 maternal deaths and 1451 near-misses in public tertiary hospitals in a low-income country. BJOG: An International Journal of Obstetrics Gynaecology. 2016;123(6):928-38.

22. Tura AK, Trang TL, van den Akker T, van Roosmalen J, Scherjon S, Zwart J, Stekelenburg J. Applicability of the WHO maternal near miss tool in sub-Saharan Africa: a systematic review. BMC Pregnancy Childbirth. 2019;19(1):79.

23. Geleto A, Chojenta C, Taddele T, Loxton D. Incidence of maternal near miss among women in labour admitted to hospitals in Ethiopia. Midwifery. 2020;82:102597.

24. National Center for Chronic Disease Prevention and Health Promotion, Centers for Disease Control and Prevention.

25. Engin-Üstün Y, Sanisoğlu S, Keskin HL, Karaahmetoğlu S, Özcan A, Çelen Ş, Üstün Y, Alkan A, Ongun V, Şencan İ. Changing trends in the Turkish maternal deaths, with a focus on direct and indirect causes. European Journal of Obstetrics Gynecology Reproductive Biology. 2019;234:21-5.

26. Ahmed I, Ali SM, Amenga-Etego S, Ariff S, Bahl R, Baqui AH, Begum N, Bhandari N, Bhatia K, Bhutta ZA, et al. Population-based rates, timing, and causes of maternal deaths, stillbirths, and neonatal deaths in south Asia and sub-Saharan Africa: a multicountry prospective cohort study. The Lancet Global Health. 2018;6(12):e1297-308.

27. Kiruja J, Osman F, Egal JA, Essén B, Klingberg-Allvin M, Erlandsson K. Maternal near-miss and death incidences Frequencies, causes and the referral chain in Somaliland: A pilot study using the WHO near-miss approach. Sexual Reproductive Healthcare. 2017;12:30-6.

28. Nelissen E, Mduma E, Broerse J, Ersdal H, Evjen-Olsen B, van Roosmalen J, Stekelenburg J. Applicability of the WHO maternal near miss criteria in a low-resource setting. PLoS One. 2013;8(4):e61248. 
29. Tunçalp Ö, Hindin MJ, Adu-Bonsaffoh K, Adanu RM. Understanding the Continuum of Maternal Morbidity in Accra, Ghana. Maternal Child Health Journal. 2014;18(7):1648-57.

30. Shen FR, Liu M, Zhang X, Yang W, Chen YG. Factors associated with maternal near-miss morbidity and mortality in Kowloon Hospital, Suzhou, China. Int J Gynaecol Obstet. 2013;123(1):64-7.

31. Moudi Z, Arabnezhad L, Ansari H, Tabatabaei SM. Severe maternal morbidity among women with a history of cesarean section at a tertiary referral teaching hospital in the southeast of Iran. Public Health. 2019;175:101-7.

32. Litorp H, Rööst M, Kidanto HL, Nyström L, Essén B. The effects of previous cesarean deliveries on severe maternal and adverse perinatal outcomes at a university hospital in Tanzania. International Journal of Gynecology Obstetrics.

2016;133(2):183-7.

33. Sharma BB, Loxton DJ, Murray H, Angeli GL, Oldmeadow C, Chiu S, Smith R: A first step to improving maternal mortality in a low-literacy setting; the successful use of singing to improve knowledge regarding antenatal care. American Journal of Obstetrics and Gynecology 2018, 219(6):615.e611-615.e611.

34. Oliveira LC, Ribeiro da Costa AA. Fetal and neonatal deaths among cases of maternal near miss. Revista da Associação Médica Brasileira (English Edition). 2013;59(5):487-94.

35. Ramirez AC, Kouyoumdjian F, Liauw J, Costescu D, Lu H, Holder L. INFANT AND MATERNAL OUTCOMES IN WOMEN WHO EXPERIENCE IMPRISONMENT IN ONTARIO, CANADA: A RETROSPECTIVE COHORT STUDY. Journal of Obstetrics Gynaecology Canada. 2019;41(5):714.

36. Owolabi OO, Cresswell JA, Vwalika B, Osrin D, Filippi V. Incidence of abortion-related near-miss complications in Zambia: cross-sectional study in Central, Copperbelt and Lusaka Provinces. Contraception. 2017;95(2):167-74.

37. Liyew EF, Yalew AW, Afework MF, Essen B. Maternal near-miss and the risk of adverse perinatal outcomes: a prospective cohort study in selected public hospitals of Addis Ababa, Ethiopia. BMC Pregnancy Childbirth. 2018;18(1):345.

38. Ghazivakili Z, Lotfı R, Kabir K, Norouzi nia R, Rajabi Naeeni M. Maternal near miss approach to evaluate quality of care in Alborz province, Iran. Midwifery. 2016;41:118-24.

39. Daru J, Zamora J, Fernández-Félix BM, Vogel J, Oladapo OT, Morisaki N, Tunçalp Ö, Torloni MR, Mittal S, Jayaratne K, et al. Risk of maternal mortality in women with severe anaemia during pregnancy and post partum: a multilevel analysis. The Lancet Global Health. 2018;6(5):e548-54.

40. Mustafa R, Hashmi H. Near-miss obstetrical events and maternal deaths. 2009, 19(12):781-785.

\section{Figures}



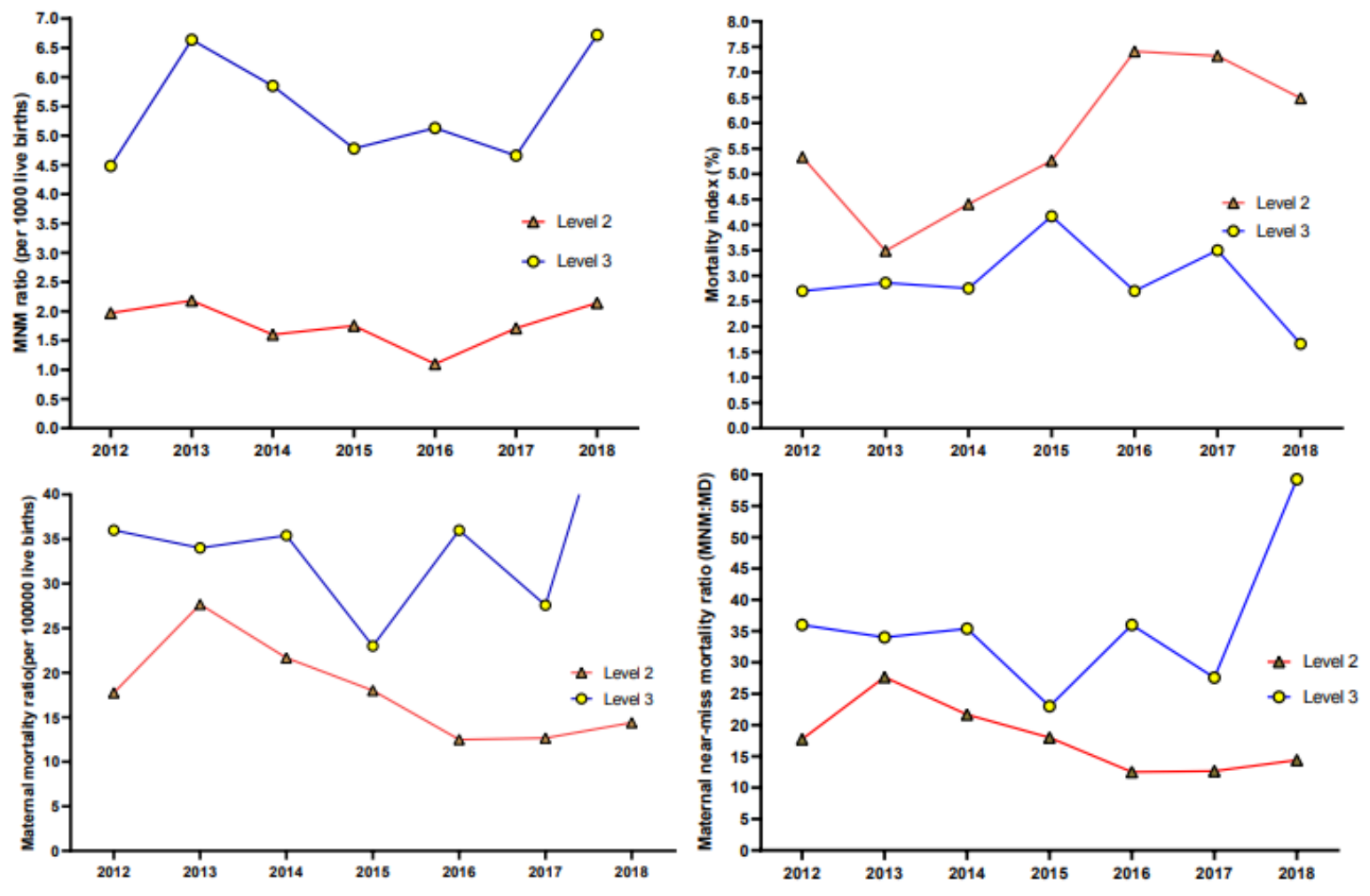

Figure 1

The time trend of MNM ratio, MI, maternal mortality, and MNM:MD in women admitted to level 2 and 3 hospitals in Hunan province from 2012 to 2018.

\begin{tabular}{|c|c|c|c|c|}
\hline $\begin{array}{c}\text { MNM-level } 2 \\
(\%)\end{array}$ & $\begin{array}{c}\text { MNM-level } 3 \\
\text { (\%) }\end{array}$ & Organ dysfunction & $\begin{array}{c}\text { Maternal deaths- } \\
\text { level } 2 \\
(\%)\end{array}$ & $\begin{array}{c}\text { Maternal deaths-level } \\
3 \\
(\%) \\
\end{array}$ \\
\hline 49.19 & 18.46 & Cardiovascular dysfunction & 20.69 & 27.66 \\
\hline 7.57 & 7.13 & Respiratory dysfunction & 24.14 & 17.02 \\
\hline 3.89 & 2.14 & Renal dysfunction & 13.79 & 2.13 \\
\hline 59.1 & 79.32 & Coagulation dysfunction & 27.59 & 42.55 \\
\hline 1.23 & 2.14 & Hepatic dysfunction & 13.79 & 2.13 \\
\hline 18.2 & 9.51 & Neurologic dysfunction & 41.38 & 17.02 \\
\hline \multirow[t]{2}{*}{16.77} & 13.63 & Uterine dysfunction & 3.45 & 0 \\
\hline & & Morbidity conditions & & \\
\hline 71.98 & 68.46 & Obstetric hemorrhage & 10.34 & 14.89 \\
\hline 8.59 & 8.64 & Pregnancy related infections & 6.9 & 8.51 \\
\hline 29.86 & 22.98 & Hypertensive disorder & 62.07 & 23.4 \\
\hline 2.45 & 4.6 & heart disease & 13.79 & 10.64 \\
\hline 2.86 & 1.51 & Embolism disease & 17.24 & 14.89 \\
\hline 4.7 & 4.68 & hepatopathy & 10.34 & 6.38 \\
\hline 71.57 & 69.49 & anemia & 37.9 & 29.79 \\
\hline 7.57 & 16.01 & diabetes mellitus & 0 & 12.77 \\
\hline 1.43 & 2.46 & nephropathy & 10.34 & 0 \\
\hline 0.41 & 2.22 & pulmonary disease & 0 & 6.38 \\
\hline 56.24 & 59.11 & With other diseases & 48.2 & 53.19 \\
\hline
\end{tabular}

Figure 2 
The proportion of organ dysfunction and maternal complications for MNM and MD cases at level 2 and 3 hospitals in Hunan province, from 2012 to 2018 